\title{
Khevsur and Tush and the Status of Unusual Phenomena in Corpora
}

\author{
THOMAS R. WIER \\ University of Chicago
}

\section{Introduction}

Recent years have seen an increasing realization of the threat posed by language loss where, according to some estimates, upwards of ninety percent of all languages may go extinct within the next century (Nettle \& Romaine 2002). What is less often realized, much less discussed, is the extent to which linguistic diversity that falls within the threshold of mutual intelligibility is also diminishing. This is especially true of regions where one particular language variety is both widely spoken and holds especially high prestige across many different social classes and communities. In this paper, we will examine two such 'dialects' of Georgian: Khevsur and Tush, and investigate what corpora-based dialectology can tell us about phylogenetic and typological rarities found in such language varieties.

\section{Ethnolinguistic Background}

Spoken high in the eastern Caucasus mountains along the border with Chechnya and Ingushetia inside the Russian Federation, for many centuries, Khevsur and Tush have been highly divergent dialects of Georgian, perhaps separate languages, bearing a relationship to literary Georgian not unlike that of Swiss German and Hochdeutsch (see map, from Hewitt 1995:vi). 
Figure 1. Distribution of Kartvelian dialects and languages.

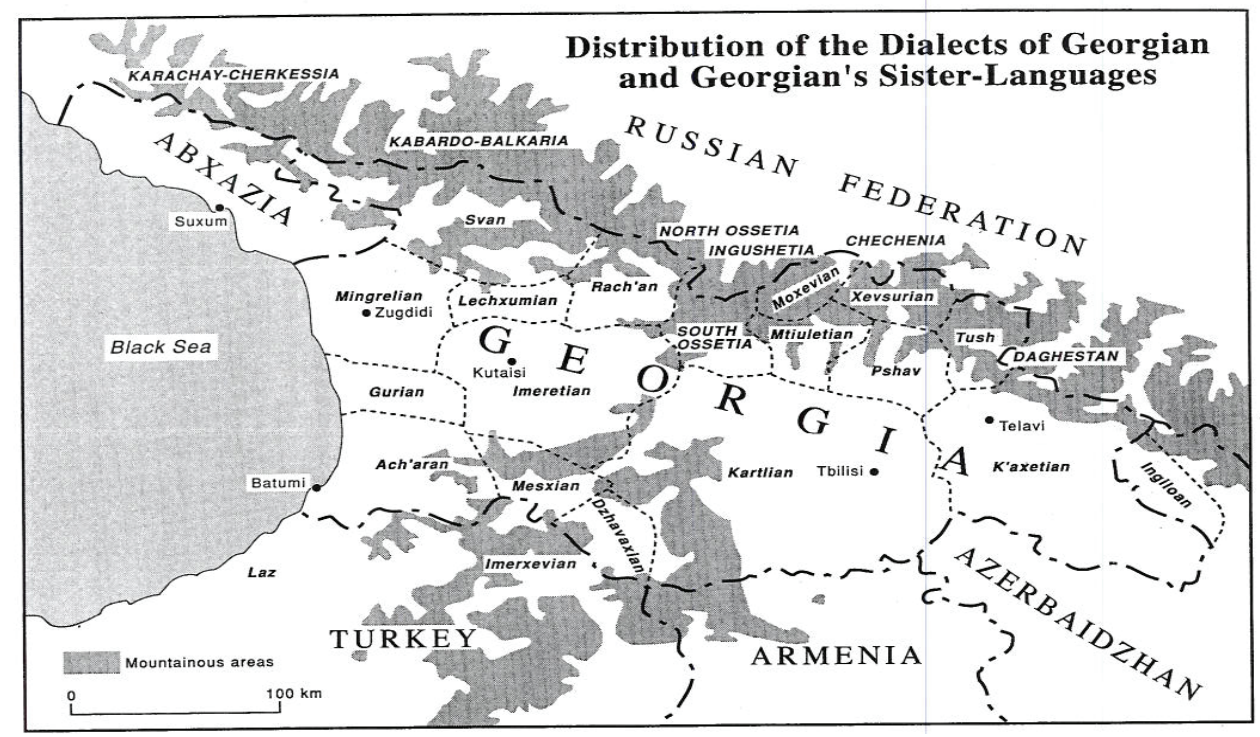

Among other reasons, for the better part of a thousand years they have had more intimate regular contact with Nakh-Daghestanian languages, and have borrowed numerous words from them: balği 'child' (cf. Lezgian bal'a 'child'), bage 'lip' (cf. Ingush and Chechen baga, Batsbi bak all 'mouth'), ali 'flame' (Ingush ala, Chechen älu, both 'flame'), riq'e 'stone' (cf. Botlikh req'a 'hill'). Independent of this, they have also developed a number of features not directly attributable to language contact, such as distinct lexical items (kood 'completely' instead of Standard sruliad, mtliad), differential suppletion patterns ( $m i-o l$ 'I'm going' vs. Standard $m$-v-di-var 'id.'), semantic shifts (Khevsur xoq'ana 'people' < kveq'ana 'land'; cf. standard xalxi 'people'), a different number system (xut-oci 'fivetwenty' = 'hundred', vs. standard asi).

On the other hand, both dialects preserve archaisms that have been lost in some or all of the other contemporary Georgian dialects. For example, both dialects preserve a contrast between an aspirated and a glottalized uvular stop /qh/ vs. /q'/ and between the glide $/ \mathrm{y} /$ and $/ \mathrm{i} /$; the former in each case has merged uniformly with the latter in the Standard. Both dialects also preserve the permansive tense-aspect morphology and syntax from Old Georgian, a kind of gnomic aorist representing events that are always true; this has been lost in other dialects, including the standard. All of these difference add up to a significant barrier in communication for most speakers of the Standard language. 


\section{Previous Corpora and the Current Study}

Previous work on Khevsur and Tush ${ }^{1}$ focused primarily on lexicography, phonological processes particular to these dialects, and idiosyncrasies of paradigm formation. While like all basic documentation work this is unquestionably valuable, and much of this work has been of very high quality, a number of problems recur throughout these texts which stand in need of improvement. Firstly, many of these dialect texts were collected more than a century ago without the aid of modern recording devices and methods of elicitation. Most such texts were transcribed by hand on site, while fragile wax-cylinders and records (to the extent they ever existed) suffered the vicissitudes of neglect and outright destruction during Georgia's complex history in the twentieth century. Furthermore, metadata about the consultants' age, sex, location and relationship to the wider community were rarely or only incompletely recorded, thus making our task of interpretation all the harder. The corpora were, without exception, published in Georgian script with all commentary and linguistic analysis in literary Georgian, with the result that these dialects (or languages) were essentially inaccessible to all non-Kartvelologists. Thus scholars working on unrelated but geographically close Nakh-Daghestanian, Abkhaz-Adyghean, Turkic, IndoEuropean and other languages were incapable of comparing how this small area interacted within the larger ethnolinguistic context. Above and beyond these problems, however, because the dialects themselves have in all likelihood been greatly restructured in the direction of the standard language, or replaced by some sort of Umgangsprache, it is difficult to know whether recordings and elicitations made today are capturing the 'same' language form as that recorded a century ago. Given that any dialect of Georgian, whatever its form, also generally lies at one extreme of complexity in terms of morphosyntax among the world's languages, even specialists can have a hard time penetrating the labyrinthine relationships between paradigms, argument structure, and clausal architecture. 
Status of Unusual Phenomena in Corpora

Figure 2. Example Khevsur text:

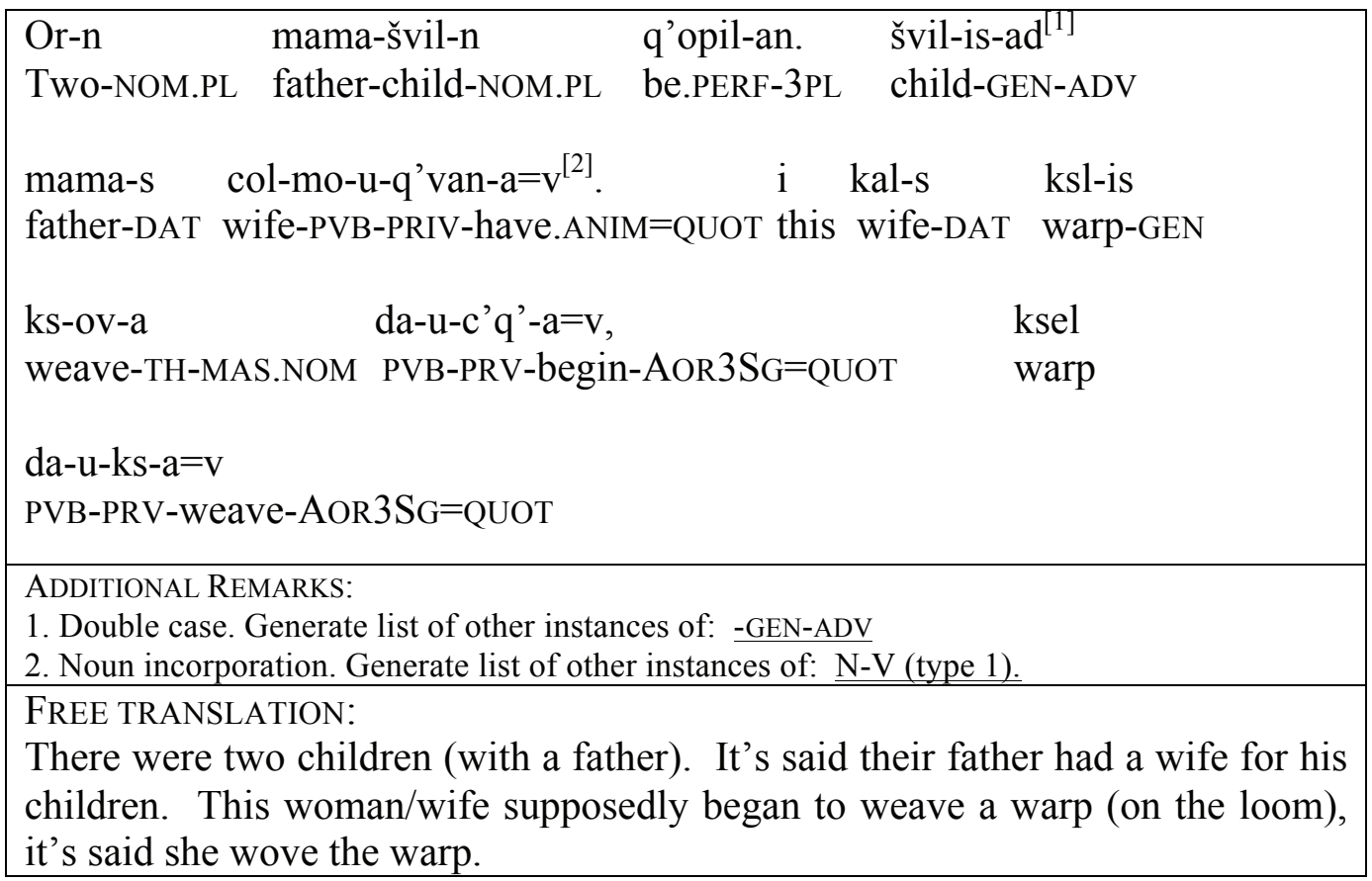

(This text taken from Shanidze 1984)

The current study seeks to correct some of these problems by making full use of modern technology and approaches through an online digital dialect corpus. This gateway, modelled in part on the Perseus Project at Tufts University and Jost Gippert's TITUS-Projekt in Frankfurt, when completed will gather and present glossed and translated dialect texts in Georgian and Latin script in which each word is hypertexted to a dialect dictionary allowing scholars to see the cloud of meanings a given lexical entry may have. Beyond this textual level however the corpus envisions both intratextual and intertextual metatextual annotations of how a given text relates to the language and other texts in the corpus. Thus, intratextually, constructions which vary from standard Tbilisi Georgian, or from typologically expected norms, will be flagged to allow scholars unused to the norms of Kartvelian to focus on and potentially explain such differences.

Intertextually, constructions and forms in a text which differ from other texts in the corpus, either by different speakers, recorded in different locations or from different time periods, will be marked as such. This dual approach will allow scholars to see how all a given form behaves across a variety of constructural contexts. Furthermore, the digital recordings (both audio and video, where available) from which these texts were made will be made available along with each text, so that users can actually isolate the constructions in context. The goal is to give corpus users the fullest possible understanding of language use from a variety of different perspectives. 
Thomas R. Wier

\section{$3 \quad$ Typological Rara in the Corpus}

\subsection{Violations of Superiority Effects in Wh-Constructions}

Such corpora tend to be 'messy' in the sense that they lack the idealization that accretes around studies based entirely on elicitation. Not only is this true of the current corpus of Khevsur and Tush, it reveals violations of typological norms not generally found in the already outré standard Georgian morphosyntactic system. So, for example, standard Georgian abides by the linguistic tendency that in constructions involving multiple wh-words an animacy restriction constrains otherwise rather free wordorder. In all varieties, such wh-words must surface preverbally (1a), and when both an animate and an inanimate wh-word are present, the animate wh-form must precede the latter (1b-c; Harris 1981:xx):

(1)
a. ra-s
a-k'et-eb-s
$(*$ ras $)$
what-DAT PRV-do-TH-3SG
'What is he doing?'
b. vin ra-s
who.NOM what-DAT
'Who is doing what?'
c. *ra-s vin
what-DAT who.NOM vin a-k'et-eb-s
a-k'et-eb-s
PRV-do-TH-3SG
PRV-do-TH-3SG

'Who is doing what?'
(St. Geo.)

Specialists who work on question constructions must often rely on elicitation because of the extreme rarity of multiple wh-constructions in corpora of natural languages. In the current corpus, however, not only are there numerous whconstructions (or at least, more than expected from a corpus of considerably less than a million words), these multiple wh-constructions exhibit contrary tendencies in comparison with the standard dialect. As you can see in (2-3), in Khevsur, the wh-words still obligatorily surface before the verb complex (including negators). This is expected if all focal items surface immediately preverbally, as in Standard Georgian. However, other when you get two or more wh-words together, violations of superiority occur if one or more of the wh-words does not have a question interpretation, but rather is a homophonous indefinite pronoun (4-5).

$$
\begin{array}{lllll}
\text { ra-a }(\mathrm{d}) & \text { v-k'l-av-t=av } & \text { ar=c } & \text { as=av } & \text { čven } \\
\text { What-ADV } & \text { 1-kill-TH-PL=QUOT } & \text { not=and } & \text { be.3Sg=QUOT } & \text { 1PL } \\
\text { dana-i=v, } & \text { ra=ze } & \text { v-e-k'id-eb-i=ao=da } & \\
\text { knife-NOM=QUOT } & \text { what.DAT=on } & \text { 1-PRV-hang-TH-PF-QUOT=and }
\end{array}
$$$$
\text { ga-u-šv-es. }
$$$$
\text { PVB-PRV-wipe-AOR3PL }
$$

'Why are we killing it, it's not our knife, what will we hang it on and what will they wipe it with?' 
(3)
peq ${ }^{\mathrm{h}}-\mathrm{t}$
ra-s ča-v-i-c-om-d-i=v?
foot-DAT.PL what-DAT PVB-1-PRV-fall-TH-IMPF-1/2IMPF=QUOT
'How could I fall flat on my feet?'

(4)

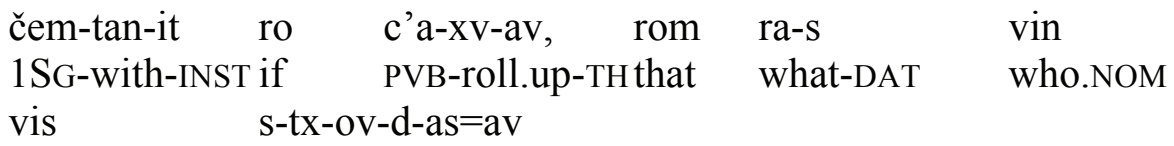

who.DAT 3-ask-TH-IMPF-3SG=QUOT

'If you will roll it up for me so that whatever [lit. 'what'] anyone [lit. 'who'] asks of anyone [lit. 'of whom']...'

(5) క̌en

$\begin{array}{llll}\text { šen } & \text { dana } & \text { ra }=\breve{s i} & \text { vis } \\ \text { 2SgPoss } & \text { knife.NOM } & \text { what=in } & \text { who.DAT }\end{array}$

š-č'ir-d-eb-od-a $=\mathrm{v}$ ?

3-need-INGR-TH-COND-COND3SG=QUOT

'As for your knife, why would anyone [lit. 'who'] need?'

This is interesting in that the morphological signaling that is usually required to obviate the underlying question interpretation to produce an indefinite in standard Georgian and western languages is not present here. Thus the templatic constraint that is present in standard Georgian (6; see Wier, forthcoming), which like these dialects also has a nonconfigurational clause structure, is weakened, in that variation in wh-word ordering occurs which does not in the standard (7). 
(6) Standard Georgian clause structure

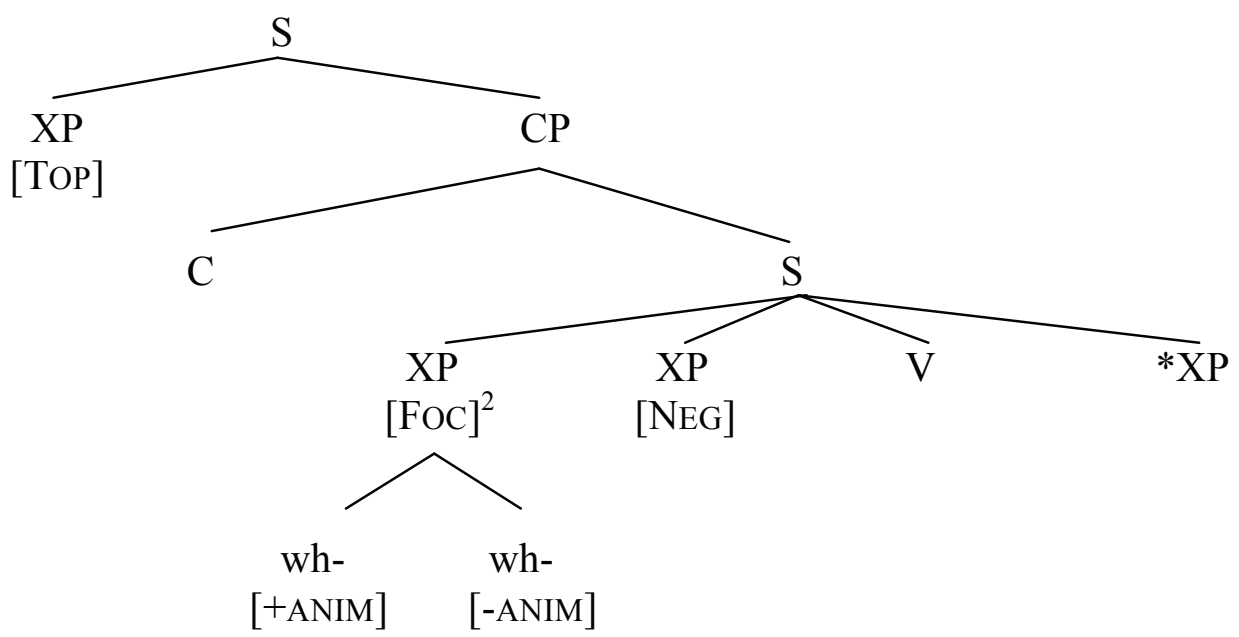

(7) Khevsur and Tush focal structure:

$\mathrm{XP}$

[FOC]

That is, in comparison with the standard, the dialectal forms simply lack any templatic specification for ordering generalizations of wh-words as long as the wh-forms are all grouped together.

\subsection{Noun Incorporation}

In standard Georgian, noun incorporation is at best a marginal morphological process, allowable only about to the same extent that it is in English with N-N compounds:

(8) a. tav-mo-q'var-e head-[AGENT-love-AGENT]

(St. Geo.) 'proud' (lit. 'head-lover')

b. c'qal-c'a- ̌̆-eb-ul-i water-PVB-take-TH-PART-NOM

'a drowning person' (lit. taken by water) (Shanidze 1953:162)

For purposes of this article, I will remain ambiguous as to whether this is a grammaticalized syntactic feature which both wh-words with question interpretation and indefinite pronouns bear and which thus triggers particular orderings in the syntax, or whether [FOC] is a semantic or discourse functional feature. I believe it is probably the former, but this is really an empirical question testable by discourse analysis and beyond the scope of this article. 
These constitute the first of the by now familiar four-way typology for noun incorporation posited by Mithun $(1984,1986)$ :

(9) a. Type 1, Lexical compounding: heads reduce their valence by one, as in $\mathrm{N}+\mathrm{N}>\mathrm{N} ; \mathrm{V}+\mathrm{V}>\mathrm{V} ; \mathrm{N}+\mathrm{V}>\mathrm{V}$; etc.

b. Type 2, Manipulation of case: syntactic heads not only reduce their valence by one, another argument moves in to take its place.

c. Type 3, Manipulation of discourse structure: heads (usually verbs) incorporate their dependents (usually nouns) to background incidental information.

d. Type 4, Classificatory NI: dependents incorporate into heads to act as classifiers of a more general free dependent.

In contrast to the standard language, in Khevsur, there are a variety of examples of NI, including at least one textual attestation of Mithun's Type 4 NI (aka 'syntactic' NI). In the form in (10), for example, the root elam- 'squint' has been incorporated into the verbal root q'opil 'be' ${ }^{3}$. A number of different criteria suggest that this form has truly been incorporated. First, this particular example comes from a story that was elicited by Č'inč' arauli who was a native speaker of Khevsur dialect. The fact that a native speaker intuitively sees them as a prosodic unit suggests (though does not prove) that they are also a morphological unit. More direct evidence of this is that the accent shifts to mark the noun as part of the verbal prosodic phrase: thus the nominative suffix $-i$ receives accent in elam$i$ - instead of the initial syllable as in the free word: élam-i.

(10) Type 1: noun compounding

i kal elam-í-q'opil.

that woman squint-NOM-be.PERF

'The woman had a squinty-eye.'

Another argument that these arguments are truly incorporated into the verb is that the focal elements, which in standard Georgian must usually immediately precede the verb complex (excluding negators), here precede the incorporated noun:

$$
\begin{aligned}
& \text { (11) a-dg-a da c'a-ma-vid, ra met' } \\
& \text { PRV-stand-AOR3SG and PVB-vent-GO.AOR3 what more } \\
& \text { gza-í=a-kv... } \\
& \text { way-NOM=PRV-have } \\
& \text { 'He got up and went off, however much more he had to go...' }
\end{aligned}
$$

Perhaps most interestingly, there are even examples of Mithun's Type 4 NI in both Khevsur and Tush dialects. In the Khevsur example in (12), the incorporated

Cf. standard literary Georgian: 'is kali elami iq'o'. 
nominal mrudi 'crooked' modifies the more general nominal k'utxi 'corner', classifying it.

Type 4: 'syntactic' NI

$$
\begin{aligned}
& \text { ert } \quad \mathrm{k} \text { 'utx-i=v } \quad \begin{array}{l}
\text { mrud }-1=\mathrm{i}=\mathrm{kv}=\mathrm{av} \\
\text { crooked-NOM=have.INAN=QUOT }
\end{array} \\
& \text { one corner-NOM=QUOT } \\
& \text { '[The house is good but it }] \text { has one crooked corner' }
\end{aligned}
$$

In (13), on the other hand, we see evidence that the incorporated element need not be less general than the nonincorporated element. The incorporated nominal, kali 'woman' is modified by an external adjectival nominal ukmro 'husbandless, unmarried'.
(13) $\mathrm{Im}$
$\operatorname{saxl}=\breve{s i}$
ert u-kmr-o
kal-í-q'opil
that.OBL house=in one
PRIV-husband-PRIV
woman-NOM-be.PERF
axalgazda kal-i, i kal-s u-k'itx-a=v
young.NOM woman-NOM that woman-DAT PRV-ask.AOR-AOR3SG=QUOT
'In that house there was a certain unmarried woman, a young woman, and [the old man] asked her...'

What is more interesting, this is actually an example of subject incorporation rather a rare phenomenon crosslinguistically (Baker 1988, Spencer 1995). Although such constructions are by no means unattested crosslinguistically, within Kartvelian they are asymptotically rare, so their relative productivity in these more conservative mountain dialects/languages reinforces the importance of the study of less prestigious varieties of 'exotic' languages along with standard or more widespread varieties.

\subsection{Suffixaufnahme, or Double-Case?}

Another unusual property of these dialects that distinguishes them from standard Tbilisi Georgian is the use of double case constructions which, however, do not necessarily take part in any system of agreement. One basic kind of construction involves the use of a genitive followed by a dative, which may be in agreement with another dative marked head noun in the same clause:

$$
\begin{aligned}
& \text { (14) ša-X-q'var-d-a im col-s im-isa-s } \\
& \text { PVB-3-love-IMPF-3SG that.DAT wife-DAT that-GEN-DAT } \\
& \text { 'He fell in love with [the other man's] wife.' }
\end{aligned}
$$

Here, the genitival possessor imisas 'his' involves both a genitival suffix and a dative suffix to indicate the grammatical function of the possessum, here a dativemarked direct object cols 'wife'. This represents a conservative retention of an 


\section{Status of Unusual Phenomena in Corpora}

Old Georgian Suffixaufnahme, whereby all genitives had to agree in case and number with the possessum, as in (15) where the samebisa- 'of the trinity' takes an additional instrumental case $-y t a$ to indicate it modifies šec'evn-ita 'help-INST'. This construction still exists marginally in modern standard Georgian, but only in elliptical possessive constructions where the head becomes elided, as in (16).

$$
\begin{array}{ll}
\text { šec'evn-ita c'[mid]isa } & \text { sam-eb-isa-yta } \\
\text { help-INST holy-GEN.SG } & \text { three-COLL-GEN.SG-INST.SG } \\
\text { 'With the help of the Holy Trinity...' (Silogava 1994) }
\end{array}
$$

(16) vis

$$
\text { saxl-s e-Z-eb? čem-i amxanag-isa-s }
$$

whose.DAT house-DAT PRV-seek-TH my-GEN comrade-GEN-DAT 'Whose house are you looking for? My friend's.' (Boeder 2003:46)

Although rare in the standard, such constructions are quite common in both Khevsur and Tush; among the current texts in the corpus, at least $22-i s a-s$ constructions occur in the Khevsur corpus ( $10 \mathrm{k}$ words) and 6 times in the Tush corpus ( $\sim 40 \mathrm{k}$ words). Less expected however are double case constructions which do not take part in any kind of agreement with a nominal head. There are a variety of different kinds of double case, including genitive+dative -isa-s (where in its non-agreeing manifestation it usually functions as an adjunct), genitive+nominative $-i s-i$, genitive+instrumental $-i s-i t$, genitive+adverbial $-i s-a d$, and, exceptionally, double instrumental -it-it. Although almost all of these make use of a genitival stem plus some oblique case, it is unclear that the genitive contributes any meaning to the form; rather it seems simply to serve as the building block onto which further case forms (themselves rarely bearing a consistent meaning) can attach. For example, a double genitive+adverbial frequently reflects a thematic recipient of verba dicendi as in (17) and (18) or verba sentiendi as in (19) and (20), but sometimes merely the experiencer (19), and sometimes the

\begin{tabular}{|c|c|c|}
\hline $\begin{array}{l}\text { "peq }-\mathrm{t} \\
\text { foot-DAT.PL }\end{array}$ & $\begin{array}{l}\text { ra-s } \\
\text { what-DAT }\end{array}$ & $\begin{array}{l}\text { ča-v-i-c-om-d-i=v?" } \\
\text { PVB-1-PRV-fall-TH-IMPF-1/2IMPF=QUOT }\end{array}$ \\
\hline $\mathrm{u}$-tkv-am-is & & xvar-is-ad \\
\hline V-say-TH-3 & & erd-GEN-ADV \\
\hline
\end{tabular}
thing being experienced (20). Finally, sometimes the double-case form marks the recipient, as in (21).

\begin{tabular}{|c|c|c|}
\hline diac- & $u-z e x-e b-a=v$ & "k'arg oq šam, k'arg \\
\hline peasant.woman-GEN-ADV & PRV-call- $\mathrm{TH}-3 \mathrm{SG}=\mathrm{QUOT}$ & good strap good \\
\hline mo-gv-i-mzad-e=v & me & čem st'umar-sa=v!"” \\
\hline B-1 PL-PRV-prepare-Ac & QUOT 1SG & my guest-DAT=QUOT \\
\hline
\end{tabular}


Thomas R. Wier

(19) im

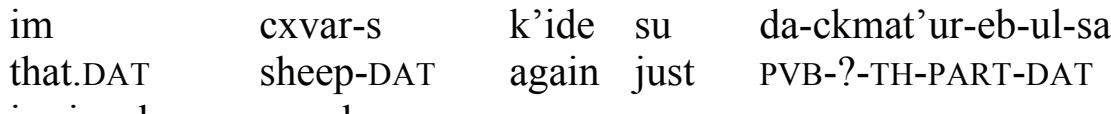

im-is-ad e-xed-v

that-GEN-ADV PRV-see.IMPF-TH

'The sheep again made [unclear] had just caught sight of him.'

( Tu)

(20) u-t'ir-is=ad memr gada-k'id-eb-ul-iq'v kmr-is-ad PRV-cry-3SG=and then PVB-irritate-TH-PART-3SGPF husband-GEN-ADV 'She cried and bugged her husband..."

(21) memr is ak'avan gē-y-k'et-a=d dē-y-c'v-in then that.NOM cradle PVB-PRV-do-AOR3SG=and PVB-PRV-burn-CAUS is balğ-i. Še-mē-y-č'ir še-mē-y-č'ir that.NOM child-NOM PVB-VENT-PRV-cut PVB-VENT-PRV-cut im ak'avan-s Še-mē-y-č'ir še-mē-y-č'ir that.OBL cradle-DAT PVB-VENT-PRV-cut PVB-VENT-PRV-cut im ak'avan-s im balğ-is-ad, that.OBL cradle-DAT that.oBL child-GEN-ADV še-mē-y-č'ir še-mē-y-čc'ir-a $=d \quad$ mē-y-k'l PVB-VENT-PRV-cut PVB-VENT-PRV-cut-Aor3Sg=and PVB-PRV-die 'Then he made the cradle and burned the little child. He dashed and smashed on the cradle, he dashed and smashed on the cradle for the child, and he dashed and smashed and he [the child] died.'

It's also worth pointing that while such double-case forms may encode obligatory arguments, as above, they can also encode optional adjuncts, as in (22) and (23) below.

$\begin{array}{lll}\text { im-is } & \text { udumliv } \quad \text { mamamtl-is } & \text { ksl-is-ad } \\ \text { this-GEN } & \text { stealthily } \quad \text { father.in.law-GEN } & \text { weave-GEN-ADV } \\ \text { gara } & \text { ga-mo-u-c'vd-av-a=d } & \text { da-u-mal-av } \\ \text { heddle.stick } & \text { PVB-VENT-PRV-reach-TH-EP=and } & \text { PVB-PRV-hide-th }\end{array}$
'She stealthily reaches for her father-in-law's heddle-stick for weaving and hides it from him.' 


\section{Status of Unusual Phenomena in Corpora}

(23)

\begin{tabular}{|c|c|c|c|}
\hline im & $\begin{array}{l}\text { beber }^{4} \\
\text { old.man }\end{array}$ & $\begin{array}{l}\text { diāyc-s } \\
\text { old.woman-DA }\end{array}$ & $\begin{array}{l}\text { k'ide } q^{\text {hel }} \\
\text { again hand }\end{array}$ \\
\hline E-y-vl- & & im & napot'-is-ada $=d$ \\
\hline & eize- $A O R 3$ & that & roach-GEN-ADV=and \\
\hline$-y-\breve{g}-0=d$ & & k'idoban=ši & čè-y-d-v. \\
\hline B-PRV-take- & $\mathrm{R} 3 \mathrm{SC}$ & $\mathrm{bin}=\mathrm{in}$ & PVB-PRV-p \\
\hline
\end{tabular}

'The old man took the woman by the hand and brought it to the roach and put it [the roach] in the bin.'

The genitive+adverbial double-case construction predominate throughout the texts. However, as noted above, most of the other logically possible combinations of genitive plus another case are possible. In (24), we see a postposed genitival modifier $k$ 'ac-is-i 'man-GEN-NOM' agreeing in case with the head noun gon- $i$ 'thought-NOM'.

\section{-is-i [GEN-NOM]}

(24) gon-i k'ac-is-i m-kon-d-a, magre thought man-GEN-NOM 1SG-have.INAN.IMPF-IMPF-3SG

but zağl-i v-i-q'av-i dog-NOM 1-PRV-be.IMPF-1/2

'I had the thought of a man, but I was a dog'

In (25), we see a genitival form d̆g-is-ita 'day-GEN-INST' which functions as an adjunct of time:

\section{-is-it [GEN-INST]}

(25) c'a-vid-o=d PVB-go.AOR-OPT $3 \mathrm{SG}=$ and is $\quad k^{\prime}$ ac- $\mathrm{i}$ da-i-c'q'-eb-d-a this.NOM man-NOM PVB-PRV-begin-TH-IMPF-IMPF3SG force-DAT day-GEN-INST=too ša-i-zl-eb-od PVB-PRV-can-TH-COND 'The man went, [and] really got a start. By day he was able.'

Finally, we also find examples of multiple exponence of the same case, as in (26), where one instrumental case suffix is followed by another identical case suffix

\footnotetext{
$4 \quad$ Interestingly, this argument lacks the expected narrative case suffix $-m$ (standard Georgian $-m a$ ). It does however use the oblique form of the article used for the narrative case, rather than the nominative case of the article is. This is another example of a shift from headmarking to dependent-marking in these dialects.

$5 \quad$ In standard such postposed modifiers are, rarely, possible in high literary style, but they would be constructed differently in the nominative: goni k'ac-isa, where the suffix -isa is the extended form of the genitive from Old Georgian used in relics like this.
} 
apparently with no difference in meaning from the standard form $i k$-it [there-INST] 'over there':

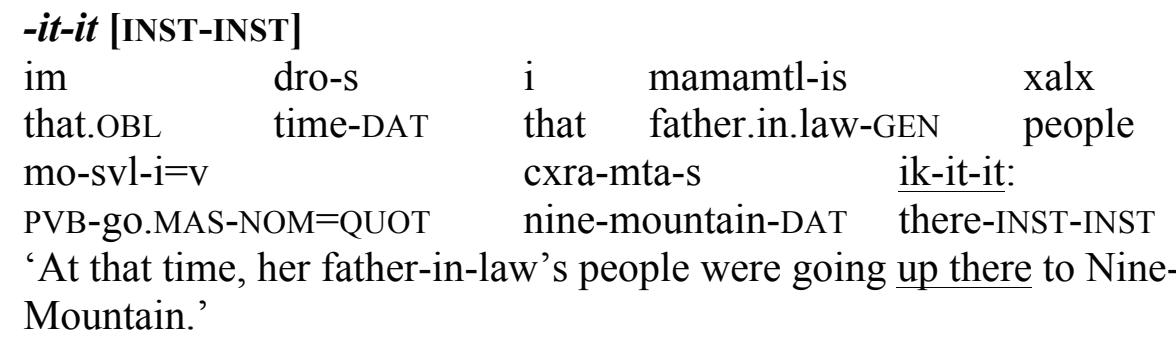

What is interesting about most of these double-case constructions is that they do not fit into standard discussions of the phenomenon of Suffixaufnahme, in which dependents must agree with heads in case and perhaps other features for the simple reason that in most of the above cases there is never any evidence of a head noun with which the nominal in question could stand in agreement. Even when the doubly-marked noun serves discourse-functionally as a modifier, as in (21), it does always do so syntactically, as when bal̆g-is-ad [child-GEN-ADV] 'for the child' stands as a sentential adjunct and the extra case does not agree with that which it discourse-functionally modifies, ak'avan-s [cradle-DAT].

An immediate question thus arises: if these doubly marked constructions do not uniformly arise from some process of agreement, as they would have in Old Georgian, where do they come from? One intriguing possibility is that they result from language contact with $\mathrm{Nakh}$ languages to the immediate north of the Khevsur and Tush dialect regions in Georgia. As noted above, these dialects have for many centuries been in contact with Chechen, Ingush, Bats, and other North Caucasian languages, which have the unusual property that oblique cases do not attach directly to the nominal root, but rather to a stem formant exclusively used for obliques. These oblique stem formants vary both in form and distribution across Nakh-Daghestanian languages, but typically behave much like the Archi and Batsbi forms in (27) and (28) below:

(27) Archi (Diana Forker p.c.)

a. gel

cup.ABS.SG

b. gel-li-s cup-OBL-DAT 
(28) Tsova-Tush (Holisky and Gagua 1994)

\begin{tabular}{|c|c|c|}
\hline & 'bear' & 'broom' \\
\hline Nom & ča & kož-o \\
\hline GEN & ča-i- ${ }^{n}$ & kož-ni- ${ }^{n}$ \\
\hline DAT & ča-i-n & kož-ni-n \\
\hline ERG/INST & ča-i-v & kož-ni-v \\
\hline $\mathrm{CON}$ & ča-i-x & kož-ni-x \\
\hline AlL & ča-i-go & kož-ni-go \\
\hline $\mathrm{ADV}$ & ča-i-ğg & kož-ni-ğg \\
\hline $\mathrm{COM}$ & ča-i-ci ${ }^{n}$ & kož-ni-cin \\
\hline
\end{tabular}

Nominals having distinct oblique stems are not entirely rare; they occur e.g. in well-known Indo-European languages like Latin and Greek. The interest in these Nakh-Daghestanian forms lies in the fact that the oblique formant is separable but semantically vacuous from the point of view of case features. That is, although they sometimes bear other features like the singular/plural contrast in the Batsbi forms, the oblique formant serves only to provide a licit stem for the actual case suffix. It is this fact that brings us back to a discussion of Khevsur and Tush double-case, since the genitival suffix in most instances is semantically vacuous in exactly the same way, with the difference that that most of the oblique cases (i.e., those that are not nominative in the Kartvelian context) may also surface attached directly to the nominal root without any oblique stem intermediary. Thus, while the system is not identical to any Nakh-Daghestanian one, it is as if the Khevsur and Tush speakers, many of whom were also presumably bilingual in one or more other Nakh-Daghestanian language, were borrowing a constructional device from those languages but using their own indigenous resources, Suffixaufnahme, which had originally served a quite different function, to do so.

\section{Conclusion}

This survey of properties of Khevsur and Tush dialects of Georgian has shown the value of data-focused corpus studies for studies of linguistics and typology, since they have a tendency to confound traditional notions of how grammars are supposed to work. Khevsur and Tush show that even when a standard form of the language abides by supposed notions of superiority in wh-constructions, some dialects can and do violate these norms. They also show that noun incorporation may indeed vary, and even unusual forms of noun incorporation such as subject NI or syntactic NI may occur in one variety while in another variety NI is almost completely absent. Finally, most interestingly, even in languages noted for obscure construction types, such as Suffixaufnahme or double-case, nonstandard varieties of language may contain typologically unusual variants of those same construction types, rarities within rarities. 
Thomas R. Wier

\section{References}

Baker, Mark. 1988. Incorporation: a theory of grammatical-function changing. Chicago: University of Chicago Press.

Ch'inch'arauli, Aleksandre. 1960. Xevsurulis taviseburebani: t'ekst'ebita da indeksit. [Peculiarities of Khevsur: with texts and an index]. Tbilisi: Press of the Georgian SSR Science Academy.

Dolidze, Givi. 1975. Xevsuruli t'ekst'ebi: leksik'onebiturt [Khevsur texts: along with lexica]. Tbilisi: TSU Press.

Harris, Alice C. 1981. Georgian Syntax. Cambridge: CUP.

Hewitt, S. George. 1995. Georgian: a structural reference grammar. Philadelphia: John Benjamins.

Holisky, Dee, and Rusudan Gagua. 'Tsova-Tush (Batsbi)' in The Indigenous Languages of the Caucasus, 4: North East Caucasian, Part 2, ed. by Rieks Smeets, 147-212. Delmar, N.Y.: Caravan Press.

Mithun, Marianne. 1984. 'The Evolution of Noun-Incorporation.' Language (60:4): 847-894.

Mithun, Marianne. 1986. 'On the Nature of Noun-Incorporation.' Language (62:1): 32-37.

Nettle, Daniel and Suzanne Romaine. 2000. Vanishing-Voices: the Extinction of the World's Languages. Oxford: OUP.

Shanidze, Ak'ak'i. 1953. Kartuli gramat'ik'is sapuzvlebi [Foundations of Georgian Grammar]. Tbilisi: TSU Press.

Shanidze, Ak'ak'i. 1984. Txzulebani tormet' t'omad, Vol. 1: kartuli k'iloebi mtaši. [Compositions in twelve volumes: Georgian dialects in the mountains]. Tbilisi: TSU Press.

Dr. Thomas R. Wier

Dept. of Linguistics

1010 E. $59^{\text {th }}$ St.

Chicago, IL 60615

trwier@uchicago.edu 